FROM: Flaherty JP, Garcia-Houchins S, Chudy R, Arnow PM. An outbreak of gram-negative bacteremia traced to contaminated O-rings in reprocessed dialyzers. A nn Intern Med 1993;119:1072-1078.

\section{Legal Guide for HIV-Infected Healthcare Workers}

The American Association of Physicians for Human Rights (AAPHR), announced the publication of "The Legal Rights and Obligations of HIV Infected Health Care Workers." The 47-page guide provides information on employment discrimination, state policies on HIV-infected healthcare workers, informed consent law, privacy and confidentiality, and insurance issues. Ben Schatz, AAPHR's Executive Director said that AAPHR also launched the Medical Expertise Retention Program to provide a variety of support services for HIV-positive physicians and other healthcare workers. The guide is available from AAPHR, 273 Church St., San Francisco CA 94114; telephone (415) 255-4547.

\section{Blue Cross and Blue Shield Extends Occupational HIV Coverage to All Its Employees}

Blue Cross and Blue Shield of Massachusetts has insured all of its employees against occupational HIV infection. A spokesperson for the company said that it was one of the most generous plans in the country. Under this plan, any Blue Cross and Blue Shield of Massachusetts employee, including medical, professional, administrative, and maintenance employee, who tests positive for HIV within a year after reporting an occupational exposure, is eligible for benefit payment four times the affected person's salary with a maximum of $\$ 500,000$ and a minimum of $\$ 100,000$. This benefit is an extra layer of protection beyond other coverage and will not affect the worker's eligibility for workers compensation for a job-related illness.

\section{9th International Congress of Chemotherapy to Be Held in Montreal in July 1995}

The 19th International Congress of Chemotherapy will be held in Montreal, Canada, July 16-21, 1995. The goal of this conference is to improve clinical care and the quality of life of patients suffering from infectious diseases and cancer. Top- ics of symposia, workshops, panel discussions, and case studies will include prevention, advances in rapid diagnosis, chemotherapy, clinical drug trials, and emergence of drug resistance. For additional information, contact the 19th ICC Secretariat, 205 Viger Ave. West, Suite 207, Montreal, Quebec, Canada H2Z 1G2.

\section{Intravenous Immune Globulin Removed from World Market}

In response to inquiries regarding an action by Baxter Healthcare Corporation to remove an immune globulin intravenous (IGIV) product, Gammagard R, from the market, the Food and Drug Administration (FDA) issued a news release confirming the action. The product, Gammagard, also is distributed as Polygam $\mathrm{R}$ by the American Red Cross.

The Hyland Division of Baxter Healthcare Corporation of Glendale California has removed its IGIV products from the worldwide market because of their possible implication in the transmission of hepatitis, including hepatitis C. Baxter recently reported that three patients in Spain and two in Sweden have been found to have hepatitis $C$ virus (HCV) infection after receiving Baxter's IGIV product. Additional patients have evidence of hepatitis and remain under study. On the basis of the temporal association with product administration, the FDA regards these cases as potentially having resulted from administration of the IGIV. However, no cases of viral transmission from this product have been confirmed.

Baxter's IGIV products are derived from human blood plasma and are used to treat a number of congenital and acquired immunological abnormalities. In contrast, a different product, intramuscular immune globulin, is used to prevent hepatitis A in travelers and for other conditions. There are also specific immune globulins used for other medical purposes, including prevention of $\mathrm{Rh}$ sensitization, tetanus, or rabies. None of these other products is affected by this action.

All donors of plasma that is used to manufacture injectable products for the treatment and prevention of disease are screened to exclude infections with five bloodborne agents, including HCV, hepatitis B, and HIV Although no cases of viral infections including HIV have been causally linked to any immune globulin product (intravenous or intramuscular preparation), as an extra precautionary measure, the FDA announced that it has been working with all manufacturers to ensure that viral inactiva- 
tion processes are adopted for these products. FROM: FD A Talk Paper February 25, 1994.

\section{CDC Establishes Private Foundation to Supplement Budget}

The CDC is establishing a private nonprofit foundation to supplement its budget. Leaders of the effort include William Foege, a former director of the CDC, and Charles McTier, president of the Robert W. Woodruff Foundation in Atlanta. The U.S. Congress authorized the creation of the National Foundation for the Centers for Disease Control and Prevention Inc in
1992. A private source of funding would enable the agency to implement projects more quickly and outside the realm of the normal and often slow budgetary process. Money raised by the new foundation would be dedicated to activities such as training programs, fellowships for public health workers, and creation of a public health museum, scheduled to open in time for the 1996 Summer Olympic Games in Atlanta.

Additional news items in this issue: $\mathrm{N}$ o H IV -2 Positive Blood Found After Almost Two Y ears of Testing (page 323) and Computer-Based Epidemiologic Case Study A vailable from CDC (page 328). 